\title{
EXPANSÃO DE CAETITÉ E FORMAÇÃO DAS NOVAS PERIFERIAS URBANAS: OS BAIRROS NOSSA SENHHORA DA PAZ E SÃO VICENTE
}

Sandra Lícian Sacramento Neves de Jesus Mestra em Geografia (PPGeo/UESB) Professora da Rede Estadual da Bahia sandralneves@yahoo.com.br

\author{
Janio Santos \\ Doutor em Geografia e Professor Pleno (DCHF/UEFS) \\ Professor Permanente (Planterr/UEFS) \\ Professor Colaborador (PPGeo/UESB) \\ janiosantos@yahoo.com.br
}

\begin{abstract}
RESUMO
O objetivo deste artigo é analisar a cidade pequena enquanto construção socioespacial dos conflitos entre classes, que se expressam em conteúdos e na morfologia urbana, e aprofundam a divisão do trabalho na escala intraurbana, com recorte para Caetité. A metodologia centrou-se em pesquisas bibliográficas, documentais e de campo, tais como aplicação de entrevistas e mapeamento de informações, as quais contribuíram para identificar os vetores da formação das periferias em pequenas cidades. Compreender a dialética espacial as compõem, como resultantes das relações político, econômicas e sociais desenvolvidas no tempo, sustenta as bases estruturais que garantem a composição de conjuntos periféricos também nos pequenos espaços urbanos, cujo desenho espacial revelase em periferias pobres e de alto poder aquisitivo, que se diferenciam-se de modo peculiar e revelam complexidades da urbanização.
\end{abstract}

Palavras-Chave: Morfologia Urbana. Novas periferias. Expansão urbana. Caetité.

\section{EXPANSION OF CAETITÉ AND FORMATION OF THE NEW URBAN PERIPHERIES: THE NEIGHBORHOODS NOSSA SENHORA DA PAZ AND SÃO VICENTE}

\begin{abstract}
The objective of this article is to analyze the small city as a socio-spatial construction of conflicts between classes, which are expressed in the contents and in urban morphology, and reveal the division of labor in the urban space, with a focus on Caetité. The methodology was based on bibliographic and documentary research, and on interviews and mapping, which contributed to identify the vectors of the formation of peripheries in small cities. Understanding the spatial dialectic, as a result of the developed political, economic and social relations, supports the structural bases that guarantee the composition of peripheral areas also in small urban spaces and the spatial design reveals poor and status peripheries, which differ in a peculiar way and reveal complexities of urbanization.
\end{abstract}

Keywords: Urban Morphology. New peripheries. Urban expansion. Caetité.

\section{INTRODUÇÃO}

O presente artigo é resultante das atuais reflexões acerca das mudanças ocorridas nas cidades pequenas, com recorte para o município de Caetité, na Bahia, em que, sobretudo em décadas mais recentes, usa seu espaço com novos fins. O objetivo é analisar a cidade pequena enquanto construção socioespacial também dos conflitos entre classes, que se expressam em conteúdos e na morfologia urbana, e aprofundam a divisão do trabalho na escala intraurbana. Compreender a dialética espacial que alicerça as periferas urbanas, como resultantes das relações político-econômicas e sociais desenvolvidas ao longo do tempo, sustenta as estruturas dos conjuntos periféricos também nos pequenos espaços urbanos.

Ao analisar as mudanças na urbanização e suas influências na construção dos bairros periféricos, com conteúdos e morfologias distintas, averiguou-se as condições de vida nas pequenas cidades e a apropriação dos direitos para compreender, no âmbito da infraestrutura urbana, as diferenças entre as periferias pobres e de maior poder aquisitivo, em que são identificadas ações do poder estatal e demais agentes produtores do espaço urbano.

$\begin{array}{llllll}\text { Caminhos de Geografia } & \text { Uberlândia-MG } & \text { v. 22, n. } 83 & \text { out./2021 } & \text { p. 187-199 } & \text { Página } 187\end{array}$


A metodologia centrou-se em pesquisas bibliográficas, documentais e de campo, tais como aplicação de entrevistas e mapeamento de informações, elementos que contribuíram para identificar os vetores que influenciam a formação das periferias em pequenas cidades, particularizadas por Caetité.

O texto está organizado em três tópicos e inicia com abordagens teóricas sobre morfologia urbana e novas periferias, seguidas da análise sobre a expansão urbana de Caetité. Por final, é tratada a formação das periferias distintas que estruturam a cidade atual.

\section{MORFOLOGIA URBANA E NOVAS PERIFERIAS NAS CIDADES}

A palavra morfologia vem do grego morphe e logos, e sua etimologia a define, de acordo com Ferreira (2010), como forma e estudo, respectivamente; em síntese, o "estudo das formas". No campo multidisciplinar, a morfologia apresenta diversos conceitos, a exemplo: Geografia Urbana, que enfatiza as frações espaciais que descortinam a paisagem; Linguística, que permeia os processos de classificação, origem e flexão das palavras; Botânica, que analisa a composição vegetal; e Geomorfologia, que estuda a origem o relevo.

Todas essas concepções não serão avaliadas, posto que se busca analisar a morfologia sob o enfoque da Geografia Urbana. E essa, quando adjetivada de "urbana", indica múltiplas acepções que a qualificam como: área de conhecimento, que, na interpretação de Mendes e Cabrita (2012), investiga as formas pela sua função, com a finalidade de elucidar eventos que contribuem na estruturação das cidades; pode ser análoga aos métodos dialético, analítico, dedutivo e sistêmico, que definem procedimentos; e, por fim, para Miyazaki (2013), Fernandes (2010), Sposito (2004), Meneses (1996), Aragão (2006) e Nascimento (2013), se traduz como viés para compreensão das novas periferias urbanas. E é essa última perspectiva que embasa o texto em tela.

Aragão (2006) destaca a morfologia urbana como um conjunto que, ao agrupar equipamentos históricos, econômicos e sociais, sob a ótica urbanística, reúne relações sociais e usos materializados no espaço. Uma espécie de desenho que se forma num arcabouço que muito se assemelha a um corpo funcional, devido a interligação entre a ordem sistêmica de usos dos objetos. Por outro lado, a difere das acepções arquitetônico-urbanísticas que consideram a descrição de apenas um elemento que não representa o desenho interconexo com o todo.

Portanto, trata-se do conceito-chave que explica as composições estruturais das cidades, ao partir de pressupostos, como o geoprocessamento, associados às temáticas socioculturais, políticas e econômicas, o que, para Miyazaki (2013), permite pensar as transformações urbanas. A morfologia urbana explica e é produto das imposições do capitalismo na materialização das formas e elementos que produzem o espaço urbano, dentre os quais cita-se: os tipos de construções e o desenho.

Numa parte das visões geográficas, a morfologia urbana limitou-se a ser tratada como um dado momento da análise descritiva das formas. Contudo, no entendimento de Miyazaki (2013, p. 30), "[...] mesmo se restringindo apenas à descrição do visível num primeiro momento, mostrou ser necessário buscar compreender, posteriormente, as dinâmicas e processos que levaram à configuração da forma em questão [...]".

Para Sposito (2004), quando se considera a definição de morfologia apenas no sentido etimológico da palavra há possibilidade de eliminar análises sólidas, no tocante ao estudo das cidades e do urbano, visto que sua caracterização está para além da mera percepção das formas. É primordial apoiar-se na tipologia, que implica em várias acepções para os estudos das formas e conteúdos urbanos.

Para Meneses (1996), fazer leituras históricas-geográficas é primordial para se entender as proporções, o eixo físico e o feitio de quadras, que fazem da cidade um artefato complexo, organizado à imagem da reprodução do capital. O autor lança inquietações quando infere que a morfologia urbana ainda não é totalmente inclusa como conceito para a ciência geográfica. Nisso, reitera-se que as fontes que fundamentam os debates atuais sobre o tema reduzem suas análises às cidades grandes e médias, e desconsideram que tais estudos nem sempre se aplicam à realidade das cidades pequenas.

Os planos podem também contribuir para a compreensão da forma da cidade, mas é preciso entendêlos para refletir sobre a morfologia urbana, posto que as cidades apresentam conteúdos que identificam particularidades na formação da estrutura urbana. Sposito (2004) afirma que a simplista observação das formas nega a percepção dos diferentes períodos temporais, atemporais e dos significados dos arranjos, o que implica em análises abstrusas da forma urbana, quando feitas somente do ponto de vista do desenho dos objetos estruturados na paisagem.

Nas observações de Miyazaki (2013), a planta da cidade é, portanto, a culminância de sua história, que não limita o entendimento da composição apenas ao aparente: "[...]. Se apreender a forma apenas a partir da forma em si não é suficiente, temos que reunir esforços no sentido de assimilar os conteúdos

$\begin{array}{llllll}\text { Caminhos de Geografia } & \text { Uberlândia-MG } & \text { v. 22, n. 83 } & \text { out./2021 } & \text { p. 187-199 } & \text { Página } 188\end{array}$


das formas [...]". (MIYAZAKI, 2013, p. 30). As formas apresentam conteúdos cumulativos da dinâmica espaço-tempo.

A análise morfológica, para além das formas, possui elementos importantes para os estudos das cidades, dentre os quais destacam-se as relações que produzem o espaço urbano. Mesmo que a morfologia também esteja ligada ao sítio urbano, nega-se essa discussão, posto que as situações e formas que originam um conjunto de múltiplos elementos acrônicos e temporais diacrônicos devem ser observadas. Na visão de Fernandes (2010), essas relações acontecem em diversos contextos e subsidiam reflexões melhor elaboradas da forma urbana.

A morfologia urbana ganha robustez face à análise de processos e lutas sociais, elementos intrínsecos às formas e aos conteúdos que, por exemplo, expandem o tecido urbano. E Nascimento (2013) chama atenção para certas visões epistemológicas que englobem, de modo adequado, elementos arregimentados de contextos históricos diferentes.

É importante lembrar que com os avanços tecnológicos foram criadas relações (des)contínuas entre objetos, pessoas e formas, o que, no entendimento de Sposito (2001), faz com a cidade perca parte de sua unidade espacial. Assim, formam-se nós que configuram verdadeiras teias de conteúdos designativos, denominados de sistemas de redes.

Para Whitacker (2007), os sistemas de engenharia estruturados no espaço podem auxiliar a compreensão das novas morfologias urbanas. Cada cidade expressa uma configuração distinta, ainda que o modelo econômico vigente não se diferencie. Os interesses da classe dominante impõem seu modo de vida e, no contexto da luta de classes, esses não se realizam sem a resistência dos mais pobres. Por isso, a cidade revela-se junto às discrepâncias nas formas de apropriação do espaço urbano, em particular, a periferia.

Essa periferia aparece na literatura geográfica relacionada a duas escalas, ao menos: global e intraurbana. No último caso, desdobram-se outras duas perspectivas: como sinônimo de pobreza, que apresenta como característica um conjunto arquitetônico depredado, mal estruturado e ocupado pela população "excluída" (JORDÃO, 2009; CORRÊA,1986); e ante a ideia das novas morfologias urbanas, que explicam as atuais tendências das lógicas de usos e consumos da cidade, que as estabelecem como espaços que incorporam novos conteúdos, posto que também são ocupadas pela classe de maior poder aquisitivo. (MOURA, SOARES, 2009; SILVA, 2017; SPOSITO, 2004),

Na visão de Moura e Ultramari (1996), as periferias advêm das condições sociais de vida daqueles que as residem. Esse ponto se torna fundamental para compreender cada edificação e funções que compõem as particularidades que as estruturam e as definem enquanto expressões de relações de poder.

Todavia, não raro, ainda é, para a maioria dos geógrafos, apenas o local de residência dos pobres, dependente dos serviços centrais. Santos (2005) infere que há um movimento de luta pelo espaço, em que seus novos conteúdos são a uniformidade de sistemas de engenharias alinhadas, casas bem elaboradas, habitadas por pessoas da classe média e/ou mesmo da elite, que formam uma espécie de comunidade aos moldes de uma metrópole central.

As periferias urbanas são porções do espaço em que os residentes (re)constroem e autoconstroem suas vidas como expressão política, cultural, econômica e social, cujas mudanças cotidianas resultam em contrastes nas morfologias e criam novos conteúdos. Essas áreas distantes do centro, no pensamento de Sposito (2004), são estruturadas em função de processos que mobilizam equipamentos e serviços públicos, os quais oneram o preço da terra.

A pluralização da periferia advém da implantação de loteamentos que, de acordo com Corrêa (1986), atendem também às classes média e de alto poder aquisitivo, o que incorre em transformações diversas, que segregam espacial e socialmente. As articulações entre os espaços urbanos diferenciamse em virtude dos elementos que os materializam, através de diversas relações e que combinam contradições da reprodução capitalista, o que significa a concretização de formas contemporâneas de desigualdades.

Ao conceber a periferia como área de status e não exclusivamente pelo estigma de miséria, Moura e Soares (2009) analisam que a elite transformou uma fração do espaço "não urbanizado" e desvalorizado, antes ambiente da reprodução dos pobres, e reconstruiu sua cultura do isolamento, ante a ideia da marginalização.

Silva (2017) propõe o "novo" como a qualidade diferencial do tradicional estudo que envolve o centro e a periferia. $\mathrm{O}$ autor desperta para a tendência da relativa descentralização, que traz a compreensão de que as novas morfologias das periferias se distanciam da concepção de que essas são apenas espaços desprivilegiados, isso do ponto de vista do poder público, resididos somente por pobres, todavia,

$\begin{array}{llllll}\text { Caminhos de Geografia } & \text { Uberlândia-MG } & \text { v. 22, n. } 83 & \text { out./2021 } & \text { p. 187-199 Página } 189\end{array}$


marcados por complexidades de formas, usos e conteúdos.

As periferias, ao se apresentarem como expressão do lugar, revelam as relações que reorientam o urbano no mundo contemporâneo. Para Sposito (2004), os dados quantitativos não apresentam claramente os interesses que estão implícitos nas contradições que orientam as lutas de classes. Portanto, a periferia na escala da cidade não é apenas o espaço de reprodução dos pobres, ainda que também seja o espaço da pobreza.

\section{FORMAÇÃO DE CAETITÉ E A EXPANSÃO DA CIDADE}

O município de Caetité faz parte do Território de Identidade Sertão Produtivo e dista de Salvador a aproximadamente $757 \mathrm{~km}$. Limita-se, ao norte, com Tanque Novo e Paramirim; ao sul, com Ibiassucê, Pindaí e Licínio de Almeida; a leste, com livramento de Nossa Senhora e Lagoa Real; e a oeste, com Guanambi. (Figura 1). Pertencente ao Sertão Baiano, foi configurado quando as bandeiras paulistas, no contexto do ciclo econômico mineralógico no interior, impulsionaram suas primeiras aglomerações humanas, sobretudo, em virtude da descoberta de um cinturão da ametista, do ouro e da prata nas terras que formariam a cidade de Caetité (MENDES, 1996).

Figura 1 - Localização de Caetité no Território de Identidade do Sertão Produtivo da Bahia, 2018.

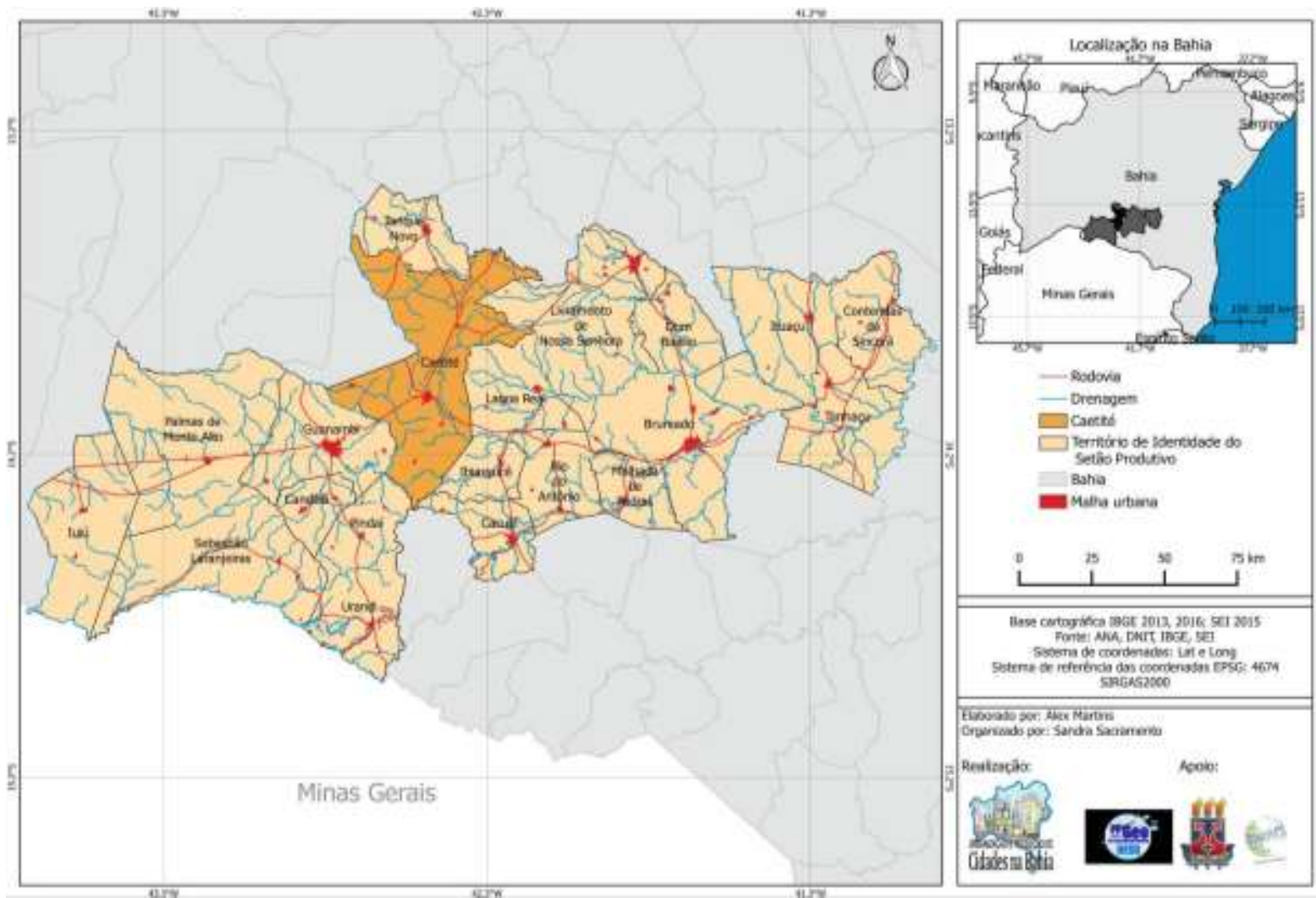

A origem da pequena cidade ocorreu no contexto da "urbanização pretérita" (SANTOS, 1993), em que se formaram inicialmente relações sociais, econômicas e políticas baseadas na exploração mineral nas sesmarias baianas e estabeleceu-se nessas terras a subordinação entre os dominados e dominadores.

Consoante Silva (1932), as terras que futuramente formariam a cidade de Caetité eram apenas um ponto de acesso, descanso e provisão para os viajantes que percorriam a rota entre Minas Gerais e as Minas de Rio de Contas. Nas acepções de Santos (1995), entre os anos de 1710-1735, passou a ser um agrupamento de fazendas que foram vendidas ou doadas pelos Condes da Casa da Torre e da Casa da Ponte. A configuração do território ocorreu em um processo secular de exploração. No século XVII se constituía como núcleo de catequese e no início do século XVIII mesclavam, dentre outras, as terras de Caitaté, Boa Vista (Brejinho das Ametistas), Barracão (Santa Luzia) e São João (Lagoa Real), que foram empossadas pelos bandeirantes paulistas, cujos atributos eram a captura de negros que fugiam de diversos núcleos coloniais, o aprisionamento de indígenas e a cobiça pelas minhas de ouro.

$\begin{array}{llllll}\text { Caminhos de Geografia } & \text { Uberlândia-MG } & \text { v. 22, n. } 83 & \text { out./2021 } & \text { p. 187-199 Página } 190\end{array}$


Em 12 de outubro de1867, Caetité tornou-se cidade, mesmo com um número reduzido de ruas pouco urbanizadas e um núcleo comercial embrionário, conforme o IBGE (1958). Entre os séculos XVIII e início do XIX, dispunha apenas de duas ruas principais: uma delas é a São Benedito, onde foi construída uma capela de mesmo nome, que abrigava políticos e autoridades influentes da época ${ }^{1}$.

Os principais edifícios de arquitetura colonial, construídos pelos clérigos, situavam-se no "Beco das Éguas". Na gestão do prefeito Odulfo Domingues (1955-1957), o beco foi extinto com fins de criar mais uma via, a qual, posteriormente, se tornou o principal acesso à Escola Normal, reaberta por Anísio Teixeira; o Hospital; a Casa do Abrigado; e a futura Feira Nova, que mudou do antigo Largo do Severino, Feira Velha, para o Largo de São Sebastião, local da atual feira livre ${ }^{2}$

As modificações nos dois palácios pontifícios, a demolição de uma casa branca, ao lado, que tinha o quintal como limite o beco, e a retirada das árvores coadjuvaram a ampliação do beco, transformado na avenida principal de Caetité, o que possibilitou a expansão da cidade para o lado oeste.

O pequeno centro, localizado nas proximidades da Igreja Matriz, recebeu novo acesso e já continha: o Mercado Público, principal equipamento de movimentação econômica da época, em que, na feira livre, se comercializavam os produtos oriundos das fazendas ${ }^{3}$; os Correios e Telégrafos; as casas estilo colonial, que abrigavam a população de alto poder aquisitivo, possuidora de renda oriunda da terra, inclusive da grande quantidade de escravos, vendidos como principal mão de obra.

A primeira expansão urbana de Caetité despontou entre os anos de 1901 a 1920, período em que a influência das famílias ricas constituiu novas instalações. Dentre outras, cita-se: o Observatório Meteorológico (1908), localizado no morro, com elevação de 90 metros acima do nível da Praça Matriz; o Colégio Jesuíta da Companhia de Jesus, em 1912; o primeiro aeroporto do Alto Sertão da Bahia; a Companhia Aérea Sadia, utilizada para transporte da elite, à época; a Diocese, sob a custódia do primeiro bispo Dom Manuel Raimundo de Melo; a instalação do Grupo Escolar Monsenhor Bastos, na Rua Barão; e o Círculo Operário, a 500 metros do núcleo central, na Av. Santana, em 19154 (Figura 2)

O leve crescimento da cidade e o adensamento urbano aconteceram quando Caetité passou a receber estudantes e funcionários públicos, descendentes de famílias ricas de outros municípios. Nessa época, parte da população pobre residia em áreas isoladas do centro embrionário, ajuntada em diversos pontos da cidade, e formou, no futuro, as periferias precárias.

Figura 2 - Expansão urbana de Caetité, Bahia, 1867 - 2016.

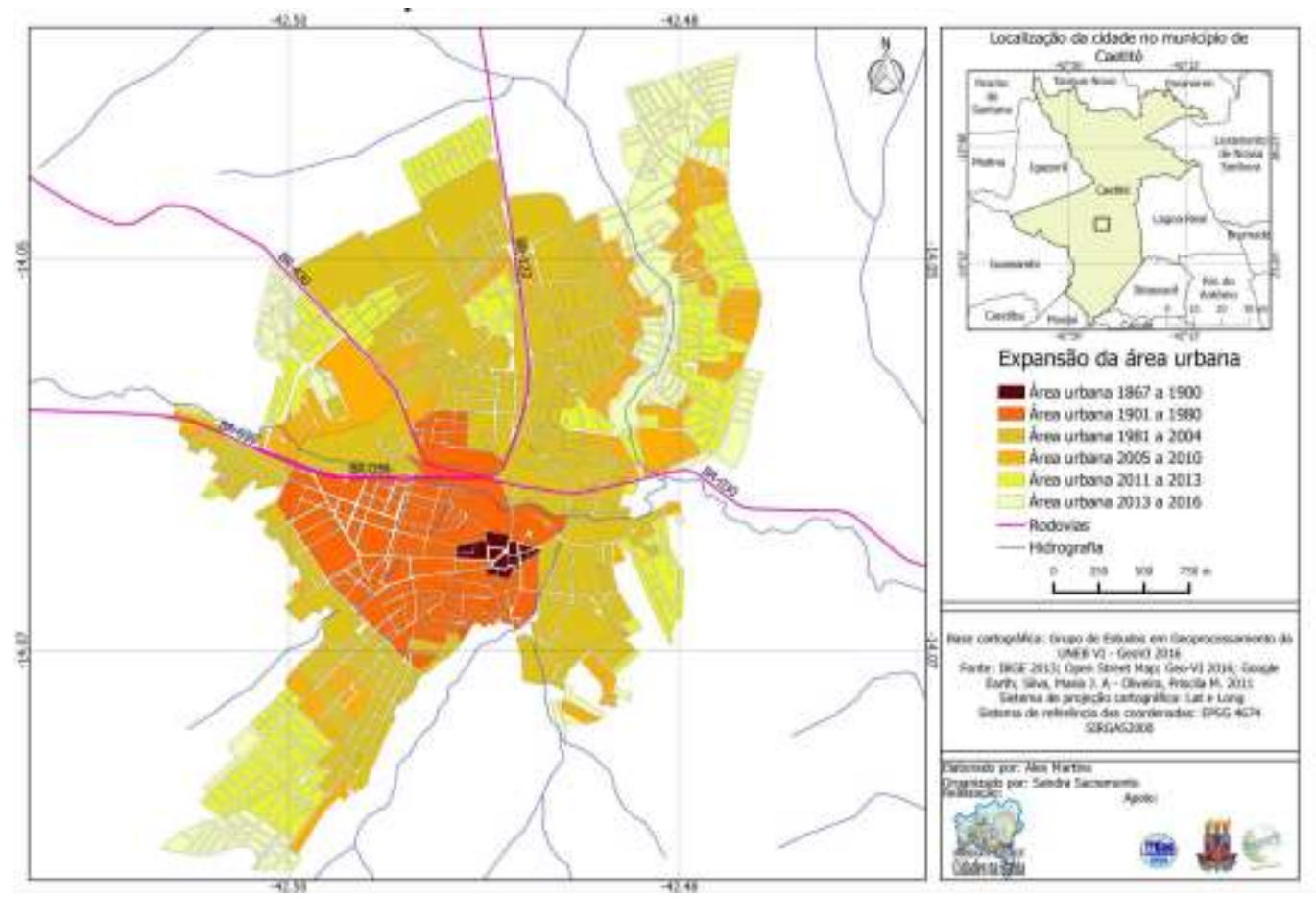

${ }^{1}$ Entrevista concedida por historiador e pesquisador em Geografia, ocorrida em 28/06/2018.

2 Informou em entrevista o pesquisador de Cultura Popular Heitor Lima na data de 04/07/2018.

${ }^{3}$ Entrevista outorgada pelo pesquisador em Cultura Popular de Caetité, na data de 04/07/2018.

${ }^{4}$ Entrevista concedida pelo historiador Kesley Souza na data 28/06/2018.
Caminhos de Geografia
Uberlândia-MG
v. 22, n. 83
out./2021

p. 187-199

Página 191 
O setor educacional, o interesse político e o estabelecimento da diocese foram, nesse primeiro momento, agentes preponderantes da "urbanização pretérita", que alteraram o espaço agrário e deram base para a consolidação do núcleo urbano. Contraditoriamente, o desemprego e a miséria foram o legado para a maioria dos negros do antigo sistema escravista, que, ao longo do tempo, ficou privada do acesso à moradia e às condições sanitárias. As periferias em Caetité foram compostas, portanto, por fatores históricos, que desencadearam na diferenciação entre as classes.

$\mathrm{O}$ antigo conjunto de fazendas foi dividido em áreas de zoneamento que agruparam, de um lado, as periferias pobres, e do outro, as áreas de maior poder aquisitivo, cujas lutas de classes marcaram o início da segregação social e espacial. Esse processo redimensionou a cidade e, paulatinamente, transformou o espaço urbano.

Caetité, em 1940, possuía 33.848 habitantes, dos quais 5.091 eram urbanos, com Taxa de Urbanização de $15,04 \%$. Desse período até 2010 , o crescimento da população urbana foi contínuo, exceto em 1960, face o desmembramento de alguns distritos. Se a população rural tendeu a redução a partir de 1980, o que revela o forte êxodo, em 2000, pela primeira vez na história, a população urbana superou a rural e contribuiu para que a Taxa de Urbanização se elevasse para 59,87\%, em 2010 (Tabela 1). Esses dados são fundamentais para compreender parte do processo de expansão urbana.

Entre as décadas de 1950 a 1970, a Prefeitura Municipal de Caetité e os proprietários fundiários foram os principais agentes que atuaram no crescimento urbano, e nisso garantiram benefícios à elite local. Tais conveniências viabilizaram a fruição de determinados equipamentos instalados na cidade.

Tabela 1 - População total rural, urbana e da cidade; Taxa de Urbanização, Caetité Bahia,1940-2010

\begin{tabular}{ccc|c|c|c}
\hline Períodos & Total & Rural & Urbana $^{1}$ & $\begin{array}{c}\text { Taxa de } \\
\text { Urbanização }^{2}\end{array}$ \\
\hline 1940 & 33.848 & 28.757 & 5.091 & 15,04 \\
1950 & 40.624 & 34.615 & 6.009 & 14,79 \\
1960 & 31.236 & 20.409 & 10.827 & 34,66 \\
1970 & 40.200 & 31.501 & 8.699 & 21,64 \\
1980 & 45.318 & 34.100 & 11.218 & 24,75 \\
1991 & 40.380 & 23.455 & 16.925 & 41,91 \\
2000 & 45.090 & 21.631 & 23.459 & 52,03 \\
2010 & 47.515 & 19.068 & 28.447 & 59,87 \\
\hline
\end{tabular}

Fonte - IBGE (1940, 1950, 1960, 1970, 1980, 1991, 2000, 2010).

Notas: 1 - São inclusas as pessoas que vivem nas sedes de outros distritos e povoados;

2 - Percentual da população urbana sobre a total.

O sucessor de Odulfo Domingues, José Neves Teixeira, prefeito em Caetité por um único mandato, fez calçamentos de ruas e mudou a feira da cidade, atual praça Rodrigues Lima, conhecida como Feira Velha, para as proximidades da BR - 030. Para isso, na década de 1960, teve que demolir um prédio monumental que existia desde o século XIX, o Mercado Público, e forçar os comerciantes a mudar para o novo mercado, nas proximidades da Rua Novo Horizonte.

A localização da Feira Nova tornou possível o crescimento da cidade em direção oeste do núcleo inicial onde, ao final dá década de 1950, no governo de Antônio Balbino, foi construído o hospital regional que, na opinião de Marques et al (2013), constituiu-se como o maior da região. Ele estruturou-se nas adjacências da Escola Normal, que deu margem à ampliação do setor educacional, o qual recentemente agregou: o Colégio Estadual Tereza Borges de Cerqueira; o Departamento de Ciências Humanas (DCH) do Campus VI; o Centro Técnico de Educação Profissional (CETEP); e um polo de Educação à Distância (EAD), do Grupo UNINTER, que alavancou a formação do bairro São José, onde foram construídos mais equipamentos, como a Rádio Educadora, o Colégio Teológico do Seminário Católico e o Centro Social Urbano.

$\begin{array}{lllll}\text { Caminhos de Geografia } & \text { Uberlândia-MG } & \text { v. 22, n. } 83 & \text { out./2021 } & \text { p. 187-199 Página } 192\end{array}$


Isso influenciou o estabelecimento do loteamento do São Vicente, que se constituiu como a periferia de status mais importante, à sudoeste do centro principal, marco fundamental para o alargamento do tecido urbano.

As edificações foram instauradas na encosta do "Morro do Piolho", área não muito valorizada, porque abrigava pequena parcela da população pobre, sobretudo negra, em um aglomerado que se limitava a duas vielas estreitas, localizadas no ponto mais alto do morro, à direita da Rádio Educadora Santana, faixa contínua de moradias, cuja maioria, composta por casebres mal estruturados, servia como abrigo.

As famílias que residiam no Morro do Piolho foram apelidadas como "proprôs" ou "piolhentos" pela "elite" local, que, para Munanga (2005), sempre generalizou pejorativamente a condição do negro. Nas reflexões de Pires (2009), por muito tempo a classe de maior renda de Caetité não considerou o negro como "gente", mas, como propriedade privada. Até mesmo suas posses foram constantemente invadidas, por considerar tais espaços eram vagos, apropriados à medida que houvesse interesse político ou econômico.

A organização de novos equipamentos no Morro do Piolho, atual bairro São José, a oeste da cidade, criou as condições necessárias para a expansão em direção ao sul e sudoeste, especialmente por impulsionar a abertura dos bairros Alto do Cristo e do São Vicente, em 1970. A criação desses implicou na ampliação do tecido urbano no sentido sul-sudoeste e deu novo formato à área ${ }^{5}$.

Entre os anos de 1981 a 2004, Caetité conheceu a maior expansão urbana, quando, por interesses do prefeito Clarismundo Pontes (1982-1988), delegou a posse de terrenos para seus correligionários. Isso ocorreu na zona nordeste, denominada de Escola Agrícola, em que as terras foram divididas em duas partes: a primeira tornou-se lotes agrícolas propriamente ditos, destinados à plantação e criação; e a segunda foi transformada em lotes urbanos, que engendraram parte do bairro Pernambuco, a Barroquinha, e o bairro Ovídio Teixeira, que compõe na atualidade a área mais populosa da sede 6 .

Houve o rápido crescimento com a venda dos lotes, o que possibilitou a expansão desses bairros, diferente do que ocorreu no São Vicente, o Santa Rita e Alto do Cristo. No bairro Ovídio Teixeira, a ocupação foi rápida, de forma que mesmo com a iniciativa da retomada dos lotes pelo poder público, nas gestões posteriores, já era completamente impossível manter o controle da compra e venda "ilegal", o que implicou na multiplicação desordenada de lotes nessa área mais plana, que agrupava mais quatro bairros: Alto Buenos Aires, Escola Agrícola, Pedro Cruz e o Santo Antônio, identificados popularmente como a "Ladeira". 7

De 2005 até 2016, o principal vetor de crescimento da cidade de Caetité, que gerou transformações urbanas significativas, foi a transferência da população da zona rural para a urbana, algo que não é novo. Na apreensão de Jordão (2009), isso também se relacionou à chegada de corporações industriais, as mineradoras e do parque eólico nos municípios do Alto Sertão, dentre eles, em Caetité, porque forçou a saída de parte da população do campo. O município conta com importantes jazidas de ametistas exploradas no Distrito de Brejinho das Ametistas desde o século XIX e a exploração atingiu o seu auge no século XX, com a instalação de uma empresa alemã.

Nota-se que a urbanização pretérita foi suplantada e os adensamentos atuais se fazem na perspectiva da nova divisão do trabalho, em que há mobilidade de capital, pessoas, indústrias e do próprio trabalho. E Caetité passa a absorver um conjunto de técnicas e de obras que permitem emoldurar-se das condições de infraestrutura, planejamento e organização administrativa consoantes à lógica.

O impacto da inserção dessas mineradoras e das multinacionais em Caetité contribuiu para a mobilidade do trabalho, o que permitiu a formação de novos espaços na cidade, assim como a ampliação do bairro São Vicente. Esses vetores de crescimento atraíram os trabalhadores das mineradoras, empresas e outros órgãos públicos e privados a fixar moradias, e criou outras demandas. Os fatos comprobatórios foram a implantação de equipamentos públicos fundamentais que corporificaram a área. Quando o poder público passou a explorar as extremidades para além do núcleo central, através da instalação de construções importantes, que melhorariam a prestação de serviços, geração de emprego e renda, impulsionou a continuidade da expansão urbana.

A partir do século XXI, Caetité avançou na criação de novos bairros, como: o Santo Antônio, Chácara e Rancho Alegre, ao norte e noroeste; ao sul, o loteamento Bosque do Jacaraci; e a sudeste, o Santa

${ }^{5}$ Para o pesquisador de Cultura Popular de Caetité, Heitor Lima entrevistado em 04/07/2018.

${ }^{6}$ Entrevista concedida pelo historiador Kesley Souza na data 28/06/2018.

${ }^{7}$ Visão do historiador Kesley Souza ao conceder a entrevista na data de 28/06/2018.

$\begin{array}{lllll}\text { Caminhos de Geografia } & \text { Uberlândia-MG } & \text { v. 22, n. } 83 & \text { out./2021 } & \text { p. 187-199 Página } 193\end{array}$


Mônica. Todos esses frutos do parcelamento de lotes, resultados e sujeitos à especulação imobiliária, que garante elevados preços e nega o direito à ocupação de pobres em determinados bairros. Um outro exemplo é o loteamento o Santa Rita, conhecido como Gambá e que teve seu crescimento no século XXI, embora suas matrizes sejam bem mais antigas, mais ou menos contemporâneas ao São Vicente. ${ }^{8}$

\section{NOVAS PERIFERIAS EM CAETITÉ: OS BAIRROS NOSSA SENHORA DA PAZ E SÃO VICENTE.}

A princípio, identificou-se os bairros o Nossa Senhora da Paz e o São Vicente como áreas que possuem morfologias distintas e exprimem a lógica de uma acumulação que se realiza no espaço urbano (Figura 3). Eles definem o substrato de um mutante arcabouço histórico, o qual agregou edificações, lotes, quarteirões, etc., em que indivíduos desenvolveram as relações para reprodução e manutenção de suas vidas.

Figura 3 - Localização dos bairros Nossa Senhora da Paz e São Vicente, 2018.

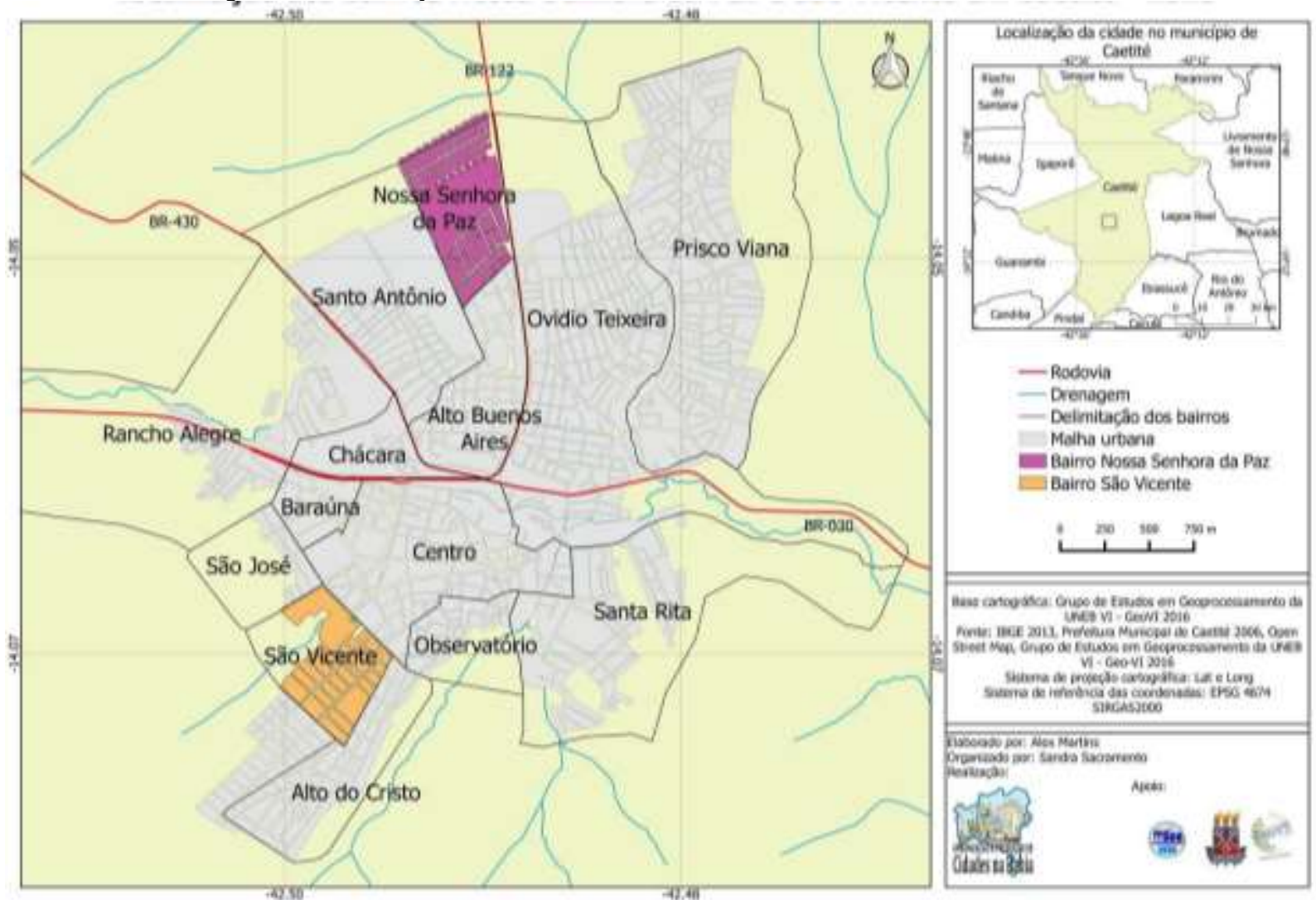

Localizado em uma área de morros, em relação ao centro da cidade, o loteamento São Vicente foi instaurado em terras privadas, da propriedade de Dr. José Carvalho, Dr. Zequinha. Ele formulou o conjunto de lotes, que assumiu formas peculiares ao agregar residências de alto padrão, ocupadas, em sua maioria, pela classe de maior renda de Caetité e cidades circunvizinhas ${ }^{9}$. Desde o início, o bairro contava com calçamento e esgoto canalizado para o rio Jatobá. Para a Prefeitura, usar o canal desse rio intermitente era uma forma de assegurar saneamento básico mais barato aos residentes. ${ }^{10}$

No bairro São Vicente, moram, sobretudo, funcionários públicos e privados, como médicos, engenheiros, professores e advogados, mas também grandes e pequenos empresários da região. A

\footnotetext{
${ }^{8}$ Visão do historiador Kesley Souza ao conceder a entrevistado na data de 28/06/2018.

9 Visão do historiador Kesley Souza ao conceder a entrevistado na data de 28/06/2018.

${ }^{10}$ Entrevista facultada pelos moradores antigos do São Vicente na data 04/07/2018.
}
Caminhos de Geografia
Uberlândia-MG
v. 22, n. 83
out./2021
p. 187-199
Página 194 
maior parte das casas é de alto padrão, com mais de $500 \mathrm{~m}^{2}$, possui piscinas, é separada por muros individuais e altos, e dispõe de poucos equipamentos públicos ou privados (Figuras 4 e 5). Trata-se de um ambiente relativamente distante da "agitação" do Centro e, principalmente, dos conjuntos habitacionais mais pobres, cuja maioria se localiza ao norte da cidade.

Figuras 4 e 5 - Padrão de residência no bairro São Vicente, 2018.

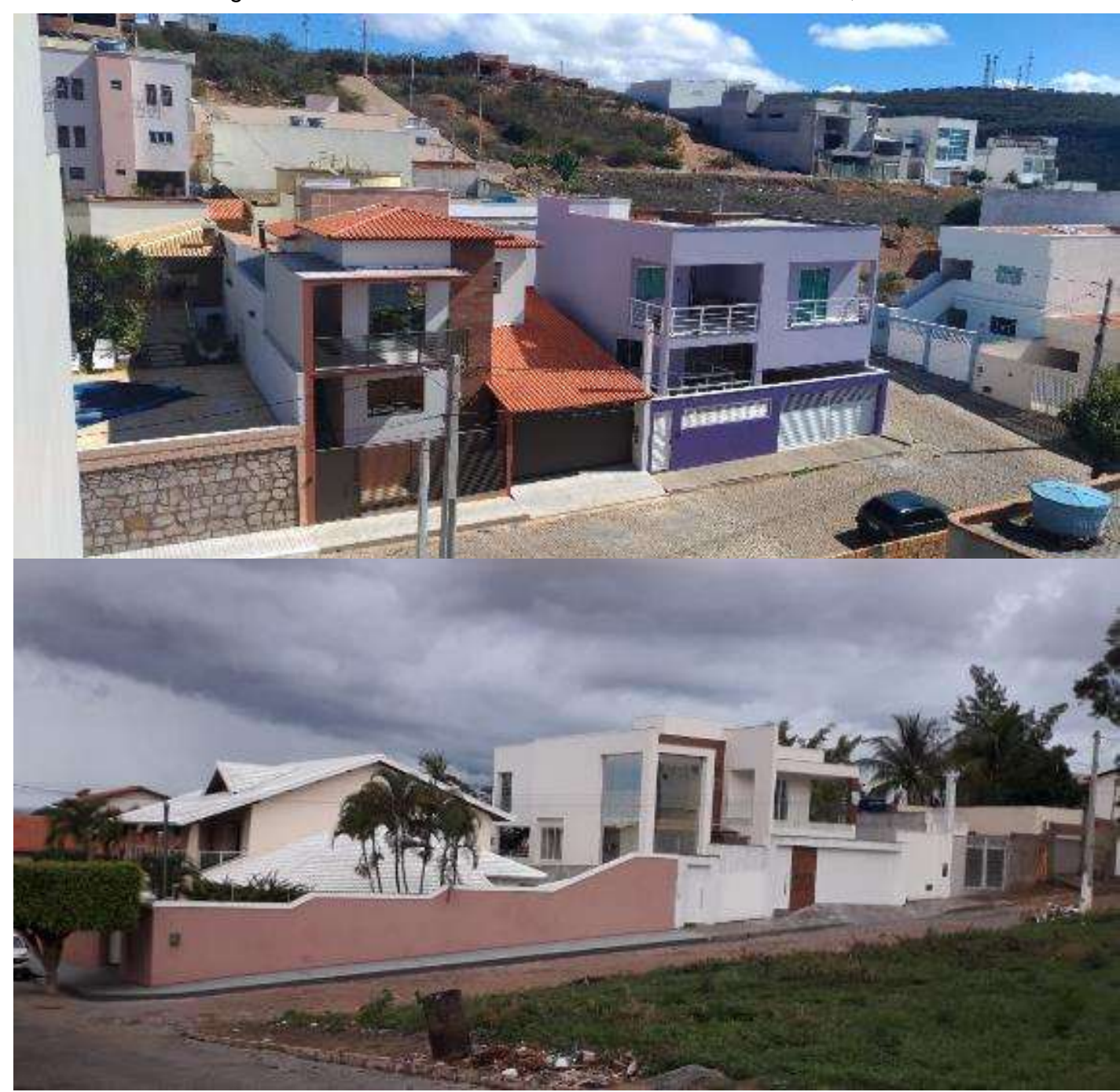

Fotos - Sandra Licien Jesus; Fonte - Acervo pessoal da autora.

Os lotes do bairro São Vicente foram comercializados por preços mais altos, o que contribuiu para a "expulsão" da maioria das famílias pobres para o outro lado da rodovia, na "Ladeira".

A ocupação dessa área de "poeira vermelha", originária da cor do solo, do qual se fazia adobe para erguer as moradias ${ }^{11}$, ocorreu no lado oposto da cidade, onde se localizava uma fazenda antiga, de relevo mais plano, denominada Barro Preto e loteada na gestão do ministro Prisco Viana, no governo de José Sarney, que apoiava o então prefeito Dácio Alves de Oliveira, eleito em 1989. Entre os anos de 1992-2000, foram construídas 350 casas populares para doação à população de baixa renda ${ }^{12}$.

Ao propagar o "sonho da casa própria", aglomerou-se a maior parte dos residentes em casebres, umas com "parede meia" e outras germinadas, com aproximadamente $22 \mathrm{~m}^{2}$ (Figura 6 ). O foco era retirar a

11 Declaração em entrevista o pesquisador de Cultura Popular Heitor Lima em 04/07/2018.

12 Idem 18.

$\begin{array}{lllll}\text { Caminhos de Geografia } & \text { Uberlândia-MG } & \text { v. 22, n. } 83 & \text { out./2021 } & \text { p. 187-199 Página } 195\end{array}$


população de renda baixa que se abrigava nas bordas das áreas de maior poder aquisitivo e nas proximidades do Centro. E essa foi a formação do bairro Nossa Senhora da Paz, onde também haviam indústrias ceramistas, que empregavam parte da população masculina do bairro. Localizado a um quilômetro e trezentos metros do cemitério, formou-se então como a outra periferia paupérrima, conhecida como "As Casinhas".

Figura 6 - Modelo das casas doadas pela Prefeitura Municipal de Caetité/BA no bairro Nossa Senhora da Paz, 2018.

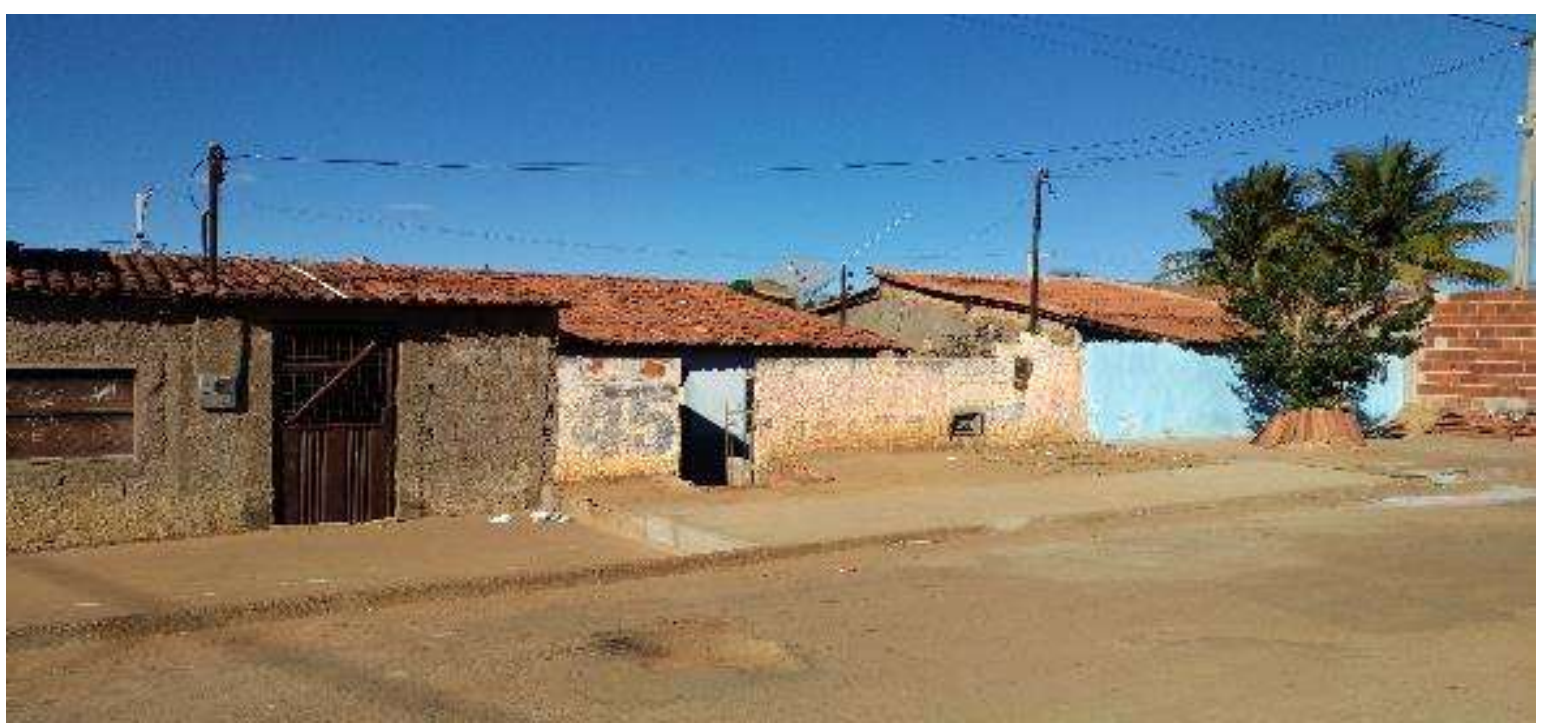

Fotos - Sandra Licien Jesus; Fonte - Acervo pessoal da autora.

A origem das famílias dos bairros em questão é diversa, pois, enquanto que a maioria dos moradores do São Vicente é natural de Caetité, seguida do grupo que veio trabalhar nas indústrias, os do Nossa Senhora da Paz têm origem na zona rural de Caetité e de outros municípios, dentre os quais: luiu, Bom Jesus da Lapa, Lagoa Real, Brumado, Jacobina, Iramaia, Guanambi e Igaporã, e chegaram em busca de trabalho.

No Nossa Senhora da Paz, os primeiros moradores eram da zona rural de Caetité. Como as casas tinham um custo mensal, vários desses, pela falta de emprego, tiveram que abandoná-las e retornaram ao campo ou migraram para outras cidades. Alguns ocupantes, também desempregados e sem condições financeiras para quitar o imóvel, passaram a residir nele clandestinamente.

As condições de vida das famílias residentes nos bairros São Vicente e Nossa Senhora da Paz denotam as discrepâncias sociais materializadas no espaço urbano de Caetité. Essas periferias são reformuladas constantemente pela dinâmica socioeconômica do município, mas também pelas características das famílias que, por um lado, são de maior poder aquisitivo e, por outro, constituem os mais pobres.

A infraestrutura assume papel primordial na distinção desses espaços e há certa lógica por trás das formas que constituem as periferias. Analisar suas características é de suma importância para a apreensão das particularidades de cada recorte espacial, a saber: as residências, as ruas e a arquitetura que, visivelmente, exprimem as desigualdades e revelam as morfologias e conteúdos impressos nas periferias.

Subsequentemente, o bairro Nossa Senhora da Paz foi ampliado à oeste, quando da atuação da Caixa Econômica Federal na construção de mais 300 casebres, destinados à funcionários públicos. Essas "Casinhas Brancas" foram abandonadas pelo público alvo e, por muitos anos, permaneceram fechadas, até que foram ocupadas por pessoas pobres de outros municípios, como Guanambi, Igaporã e Jacaraci, e da zona rural de Caetité (Figura 7).

$\begin{array}{lllll}\text { Caminhos de Geografia } & \text { Uberlândia-MG } & \text { v. 22, n. } 83 & \text { out./2021 } & \text { p. 187-199 Página } 196\end{array}$


Figura 7 - "As casinhas brancas" ampliadas pelos moradores do Nossa Senhora da Paz, 2018.

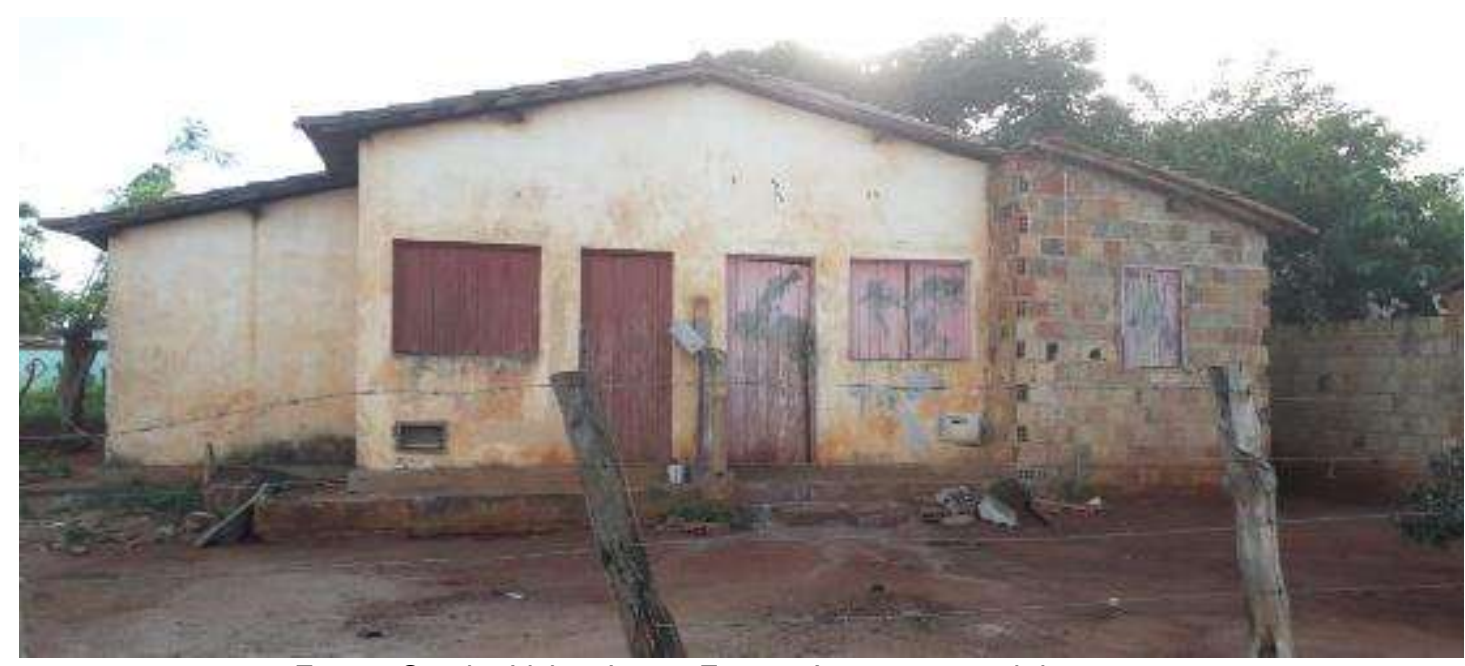

Fotos - Sandra Licien Jesus; Fonte - Acervo pessoal da autora.

Portanto, é possível identificar que Caetité apresenta na morfologia de sua periferia urbana novos conteúdos, que permitem debater o conceito clássico, uma vez que essas áreas não possuem características socioeconômicas e estruturais similares. Por um lado, é notável que esse espaço se configura por lógicas que produzem áreas de maior status, o que, por outro lado, influenciam a negação de direitos para a classe de baixo poder aquisitivo.

Os agentes que estruturaram o espaço urbano de Caetité criam lógicas diversas, as quais produziram as periferias. Dentre eles, destacam-se: os proprietários de terras e os gestores imobiliários que articulam, através das concessões da Prefeitura Municipal, os meios favoráveis ao comércio da terra urbana com diferentes preços. São esses agentes que atuam em conformidade com os proprietários dos meios de produção e os grupos sociais excluídos e resultam na formação de novas morfologias e conteúdos nas áreas periféricas.

Ao comparar a realidade das duas periferias de Caetité é possível perceber que as divergências se vertem de sua própria formação. Análogas a subconjuntos de um todo, são o sentido da circulação desigual e combinada da dinâmica de mercado local, o que cria particularidades em ambas.

\section{CONSIDERAÇÕES FINAIS}

No caso de Caetité, no decorrer do tempo e ao chegar no século XXI, o arcabouço urbano, organizado em torno de um único centro, pequeno, conduziu a dinâmica da expansão urbana. Essa conjuntura definida pelos critérios político-administrativos influenciou a morfologia urbana: um desenho segregado em periferias pobres e de alto poder aquisitivo, que se diferenciam de modo peculiar e denotam as complexidades da urbanização, em particular, a periferização.

As periferias são explicadas com base no conceito de morfologia urbana e foram analisados aspectos impressos pelas forças produtivas que impulsionam sua configuração territorial e discriminam os sujeitos sociais que as ocupam e que nelas se reproduzem. O diferencial é que na escala da cidade revelaram-se novos conteúdos e morfologias, que reposicionam o conceito de periferia apenas como sinônimo de pobreza.

O poder público municipal, juntamente com a própria dinâmica privada da acumulação, foram os principais facilitadores da configuração das periferias em Caetité e materializaram o Nossa Senhora da Paz como espaço da espoliação e o São Vicente como espaço de status. Assim, como diz Sposito (2004, p. 282), "a periferia é plural, [...] encontros, confrontos das diferenças, conhecimentos e reconhecimentos recíprocos (inclusive no confronto ideológico e político) dos modos de viver, dos 'padrões' que coexistem na cidade. [...]".

$\begin{array}{lllll}\text { Caminhos de Geografia } & \text { Uberlândia-MG } & \text { v. 22, n. } 83 & \text { out./2021 } & \text { p. 187-199 Página } 197\end{array}$


As novas morfologias das periferias consistem na implantação dos arranjos espaciais com base na lógica de uso do espaço urbano e, em parte dele, passaram a apresentar características opostas à ideia da materialização de equipamentos mal instalados, casas paupérrimas, pessoas pobres, falta de educação, dinheiro, saneamento e lazer. Vê-se que a classe dominante caetitense apropriou-se de lotes a preços elevados e construiu mansões em áreas de morro e a garantia do status se dá quando há condições para explorar tais ambientes, algo que é bem visível em outros pontos da cidade.

Percebe-se que a periferia é um arranjo espacial que se distingue da lógica do espaço central, não pela distância em relação aquele recorte, mas pela materialização de equipamento, usos, dinâmica populacional, conteúdos e funções, conforme apontado em Jesus (2019). Cada qual é a expressão da reprodução do capital e da luta de classes, que exprimem (ou não) o domínio e a sujeição capitalistas. É o meio de reprodução de vida das camadas sociais, mas também são a manutenção dos interesses da elite local.

\section{REFERÊNCIAS}

ARAGÃO, S. O estudo dos tipos-interfaces entre tipologia e morfologia urbana e contribuições para o entendimento da paisagem. Geosul, Florianópolis, v. 21, n. 42, 2006, p. 29-43.

CORRÊA, R. L. A periferia Urbana. Revista Geosul, Santa Catarina, 2ํㅗ semestre, n. 2, 1986.

FERNANDES, M. G. O estudo da morfologia urbana em Portugal. In: COLÓQUIO IBÉRICO DE GEOGRAFIA, 2, Cidades e territórios metropolitanos, Porto. Anais... Faculdade de Letras, Universidade de Porto, 2010.

FERREIRA, A. B. de H. Dicionário Aurélio Básico da Língua Portuguesa. Rio de Janeiro: Nova Fronteira, 2010, p. 214.

IBGE. Enciclopédia dos Municípios Brasileiros. Planejada e orientada por Jurandyr, Pires Ferreira. Obra conjunta dos Conselhos Nacional de Geografia e Nacional de Estatística. Rio de Janeiro: IBGE, 1958. v. XX.

IBGE. Censo Demográfico: população e habitação, 1940. Parte XII, tomo I, série regional. Rio de Janeiro: IBGE, 1950.

Censo Demográfico: Estado da Bahia, 1950. V. XX, tomo I. Rio de Janeiro: IBGE, 1955.

Sinopse Preliminar do Censo Demográfico: Brasil. 1960. Rio de Janeiro: IBGE, 1960. $\overline{\text { IBGE, } 1973 .}$

Censo Demográfico Bahia: recenseamento geral, 1970, v. 1, tomo XIII. Rio de Janeiro:

Censo Demográfico 1980: dados distritais-Bahia, v. 1, tomo 3, n. 13. Rio de Janeiro: IBGE, 1983,

Censo Demográfico 1991: resultados do universo relativos às características da população e dos domicílios, n.17-Bahia Rio de Janeiro: IBGE, 1991.

Sidra: Bando de dados sobre Censo Demográfico. Rio de Janeiro: IBGE, 2000. Disponível em: http://www.sidra.ibge.gov.br . Acesso: 05 mai. 2019.

. Censo Demográfico, Rio de Janeiro: IBGE, 2010. Disponível em: http://www.ibge.gov.br/censo2010/. Acesso: 05 mai. 2019.

JESUS, S. L. S. N. de. Novos conteúdos e morfologias na periferia das cidades pequenas: urbanização e desigualdades na cidade de Caetité - BA. 2019. 188f. Dissertação (Mestrado em Geografia)-PPGeo, Universidade Estadual do Sudoeste da Bahia, Vitória da Conquista/BA, 2019.

JORDÃO, L. C. S. novas periferias urbanas: a expansão de São Carlos através de condomínios fechados. In: SIMPÓSIO NACIONAL ESTADO E PODER, 4, Sociedade Civil, Anais... UFU, Santa Mônica, 2009.

MARQUES, Z. M. et al. 100 anos de fé e missão nas terras sagradas do sertão - Bahia. In FERNANDES, M. N.; PIRES, M. de F. N. (Org.). Diocese de Caetité. 1ed. Caetité: EDUNEB, 2013.

$\begin{array}{lllll}\text { Caminhos de Geografia } & \text { Uberlândia-MG } & \text { v. 22, n. } 83 & \text { out./2021 } & \text { p. 187-199 Página } 198\end{array}$


MENDES, B. J. Caetité: a terra a cultura e sua gente. Caetité, 1996.

MENDES, T. M.; CABRITA, M. A. Morfologia Urbana em Portugal: percurso e visibilidade. ISCTEIUL, Lisboa-Portugal, 2012, p. 1750-1781.

MENESES, U. B. Morfologia das cidades brasileiras: Introdução ao estudo histórico da iconografia urbana. Brasil dos Viajantes, 12, São Paulo, 1996, p. 144-155. https://doi.org/10.11606/issn.23169036.v0i30p142-155

MIYAZAKI, V. K. Estruturação da cidade e morfologia urbana: um estudo sobre cidades de porte médio da rede urbana paulista, 2013. 305f. Tese (Doutorado em Geografia)-Faculdade de Ciências e Tecnologia, Universidade Estadual Paulista, Presidente Prudente, 2013.

MOURA, G. G.; SOARES, B. S. A periferia de Uberlândia/MG: da sua origem até a sua expansão nos anos 1990. In: Caminhos de Geografia, Uberlândia, v. 10, 2009, p. 22-40.

MOURA, R.; ULTRAMARI, C. O que é periferia urbana. Brasiliense: São Paulo: 1996

MUNANGA, K. (org.). Discriminação racial: ideologia do livro didático. Brasília-DF: MEC/BID/UNESCO, 2005.

NASCIMENTO, A. S. Múltiplas relações entre a morfologia urbana e os shopping centers. In: Caminhos de Geografia, Uberlândia, v. 14, n. 48, 2013, p.91-104.

PIRES, M. F. N. Fios da vida: Tráfico Interprovincial e Alforrias nos Sertoins de Sima, 1860-1920. 1. ed. São Paulo, Annablume Editora, 2009.

SANTOS, H. L. Caetité pequenina e ilustre. ed. 2ª Salvador, 1995.

SANTOS, J. Políticas públicas e ações populares: O caso dos Alagados - Salvador BA. Estudos Geográficos, Rio Claro, v. 3(1), jan-jun, 2005, p. 1-18.

SANTOS, M. A urbanização brasileira. São Paulo. HUCITEC, 1993.

SILVA, A. B. O fenômeno granjeiro e os condomínios em Aldeia: uma nova periferia em conformação. Rev. Tamoios, São Gonçalo (RJ), ano 13, n 2, 2017, p. 142-152. https://doi.org/10.12957/tamoios.2017.28020

SILVA, P. C. da. Notícias Históricas e Geographicas do Município de Caetité. Revista do Instituto Geographico e Histórico da Bahia, Bahia, n 58, 1932, p. 89-294.

SPOSITO, M. E. B. A Urbanização da sociedade: reflexões para um debate sobre as novas formas espaciais. In: DAMIANI, A. L.; CARLOS, A. F. A.; SEABRA, O. C. de L. (Org.). O espaço no fim do século: a nova raridade. 2 ed. São Paulo: Contexto, 2001, 83-99.

Novos conteúdos nas periferias urbanas das cidades médias do estado de São Paulo.

Boletin del Instituto de Geografia - UNAM, Distrito Federal, México, v. n. 054, 2004, p.261-320.

WHITACKER, A. M. Inovações tecnológicas, mudanças nos padrões locacionais e na configuração da centralidade em cidades médias, Porto Alegre. In: SEMANA DE GEOGRAFIA, 9, Anais...,

Universidade Federal do Rio Grande do Sul - UFRGS, 2007.

Recebido em: 24/07/2020

Aceito para publicação em: 19/12/2020 